\title{
An 8-year study of resistance to amikacin in gram- negative bacilli isolates from patients with nosocomial infection at one hospital in Argentina
}

\author{
D. C. GARCIA, G. M. WOLOJ*§, S. PIÑEIRO\|, D. O. SORDELLI† and S. KAUFMAN $\ddagger$
}

Laboratorio de Biología Molecular, BioSidus, Buenos Aires, * Laboratorio de Bacteriología, Hospital de Niños R. Gutiérrez, Buenos Aires, †Departamento de Microbiología, Facultad de Medicina, Universidad de Buenos Aires and $\ddagger$ Hospital Juan A. Fernández, Buenos Aires, Argentina

\begin{abstract}
Summary. Administration of either gentamicin or amikacin induced an increase in the number of amikacin-resistant (AR) isolates of certain Enterobacteriaceae and Acinetobacter species in a hospital in Buenos Aires. A total of 127 AR isolates was selected to study the molecular mechanisms of resistance involved. The aac $\left(6^{\prime}\right)-I c$ gene was found by dot-blot hybridisation in every Serratia marcescens isolate. A gene different from $a a c\left(6^{\prime}\right)-I a$, aac $\left(6^{\prime}\right)-I b$ and $a a c\left(6^{\prime}\right)$-Ic encoding the AAC (6 $\left.6^{\prime}\right)$-I activity was found in a $15 \cdot 5-\mathrm{kb}$ plasmid in Acinetobacter spp. Plasmids from 27 Enterobacteriaceae contained an $a a c\left(6^{\prime}\right)-I b$ gene and 26 of these carried sequences related to the Tn1331 transposon, whereas one Escherichia coli plasmid showed homology in another fragment of the Tn 1331 transposase. Because plasmids bearing the $a a c\left(6^{\prime}\right)-I b$ gene were heterogeneous, dissemination of the $a a c\left(6^{\prime}\right)-I b$ gene may have been due to transposition of $\mathrm{Tn} 1331$ rather than the spread of an epidemic plasmid. The rate of AR isolates varied within each species in spite of the presence of $\operatorname{Tn} 1331$, and it is likely, therefore, that this transposon may not be the sole factor responsible for the observed variation. The aph(3')-VIa gene (originally described in Acinetobacter spp.) was found with high frequency $(80 \%)$ in this Acinetobacter population. Furthermore, this gene was found also in plasmids from $20 \%$ of other gram-negative organisms commonly involved in nosocomial infections in this hospital.
\end{abstract}

\section{Introduction}

Resistance to aminocyclitol aminoglycosides is an important clinical problem since these antibiotics are widely used in the treatment of serious infections. ${ }^{1,2}$ Amikacin has been the drug of choice for treating nosocomial infections refractory to other aminoglycosides. ${ }^{3,4}$ In recent years, resistance to amikacin due to production of $3^{\prime}$-aminoglycoside-phosphotransferases, $2^{\prime \prime}$-adenyltransferases and aminoglycoside- 6 '$\mathrm{N}$-acetyltransferases has been reported. ${ }^{5-8}$ In nosocomial isolates, genes encoding resistance to amikacin most frequently belong to the $a a c\left(6^{\prime}\right)-I$ group and can be encoded by plasmids or have a chromosomal locus, as is the case with Serratia marcescens..$^{5,8}$ The frequent presence of genes encoding modifying enzymes in plasmids or transposons, ${ }^{9,10}$ and, consequently, their

Received 11 July 1994; revised version accepted 19 Oct. 1994. $\S$ Present address: Schering-Plough Research Institute, Kenilworth, NJ 07033, USA.

||Present address: Department of Biology, University of Iowa, 137 Biology Boulevard, Iowa City, IA 52442, USA. capacity for dispersion, further increases the clinical problems posed by antibiotic resistance. It appears, from studies limited in each case to one institution, that the substitution of another aminoglycoside by amikacin may not necessarily be followed by a concomitant increase in resistance to the antibiotic. According to one study, predominant use of amikacin may result in a general reduction in the number of aminoglycoside-resistant isolates. ${ }^{3}$ However, other studies have described a correlation between increased amikacin use and the occurrence of enzyme-mediated resistance in gram-negative bacilli. ${ }^{4}$ In Argentina, as in many hospitals from other non-developed countries, it is very difficult to establish a relationship between clinical observations and the spread of antibiotic resistance because many variables are involved and not all can be controlled appropriately. This study was designed to analyse molecular changes that occurred in association with the emergence of resistance to amikacin over a period of 8 years in nine bacterial species isolated from patients hospitalised in the J. A. Fernández Hospital of Buenos Aires. The appearance 
of enzymes, plasmids, sequences related to $\operatorname{Tn} 1331$ and the gene responsible for amikacin resistance were investigated.

\section{Materials and methods}

\section{Bacterial strains and culture}

Escherichia coli $\mathrm{HB} 101$ pro leu thi lacY hsr hsm $\operatorname{rec} A^{11}$ and $E$. coli $\mathrm{C} 2110$ polA gyr $A^{12}$ were provided by BioSidus Laboratory (Buenos Aires), and were used in this study as recipients in transformation and conjugation experiments, respectively. One hundred and twenty-seven gram-negative clinical isolates, comprising 49 amikacin-resistant (AR) S. marcescens (49 of 110), two AR E. coli (71 of 6986), two AR Salmonella typhimurium (12 of 35), two AR Citrobacter freundii (67 of 611), 18 AR Klebsiella spp. (1520 of 4253), two AR Enterobacter cloacae (225 of 1522), two AR Proteus spp. (45 of 907) and 50 AR Acinetobacter spp. (107 of 250) were selected for the study. Numbers in parentheses represent the total number of AR isolates and the total number of isolates of each species from hospitalised patients during the period 1984-1991. Several of these species (Klebsiella spp., Serratia spp., Ent. cloacae and Acinetobacter spp.) are frequently involved in nosocomial infections whereas others $(E$. coli, Salmonella spp., C. freundii and Proteus spp.) are responsible for sporadic infections in this hospital. Isolates were identified by standard methods. ${ }^{13} \mathrm{All} \mathrm{AR}$ isolates selected for the study were resistant to five or more antibiotics, including amikacin, and were isolated from patients with nosocomial infection, i.e., patients who had been hospitalised for at least 2 days before a sample revealed a positive bacterial culture. The symptoms of infection began at the hospital and were not present prior to admission. These isolates were grown in L-broth (Sigma) supplemented with amikacin $20 \mathrm{mg} / \mathrm{L}$.

\section{Antimicrobial susceptibility tests}

Antibiotic resistance was investigated by the disk diffusion method ${ }^{14}$ in Mueller-Hinton Agar (Oxoid),

Table I. DNA hybridisation probes

\begin{tabular}{|c|c|}
\hline Probe* & Intragenic DNA fragment \\
\hline$a a c\left(6^{\prime}\right)-I a ; a a c A I$ & $\begin{array}{l}\text { 405-bp SstI fragment from } \\
\text { pFCT } 1165^{17}\end{array}$ \\
\hline$a a c\left(6^{\prime}\right)-I b ; a a c A 4$ & $\begin{array}{l}\text { 180-bp Sst / KpnI fragment } \\
\text { from pJHCMW1 }\end{array}$ \\
\hline $\operatorname{aac}\left(6^{\prime}\right)-I c$ & $\begin{array}{l}\text { 357-bp BamHI/EcoRV } \\
\text { fragment from pSCH } 2014^{8}\end{array}$ \\
\hline $\operatorname{aph}\left(3^{\prime}\right)-V I a ; \operatorname{aphA6}$ & $\begin{array}{l}\text { 370-bp EcoRI/XhoI fragment } \\
\text { from pSCH } 2010^{18}\end{array}$ \\
\hline Intragenic fragment of $\operatorname{Tn} 1331$ & $\begin{array}{l}\text { 3000-bp Bam } \mathrm{HI} / \text { Bam HI } \\
\text { fragment from pJHCMW } 1^{10}\end{array}$ \\
\hline $\begin{array}{l}\text { Intragenic fragment of the } \\
\text { Tn1331 transposase }\end{array}$ & $\begin{array}{l}\text { 2616-bp EcoRV /EcoRV } \\
\text { fragment from pJHCMW } 1^{10}\end{array}$ \\
\hline
\end{tabular}

*Please note that $a a c A 1, a a c A 4$ and aph $A 6$ are alternative, old-style nomenclature. as recommended by the NCCLS. ${ }^{15}$ Quality control of this method was performed with E. coli ATCC 25922 and Pseudomonas aeruginosa ATCC 27853 strains. The amikacin minimal inhibitory concentration (MIC), for strains characterised as intermediate or resistant according to the disk diffusion method by the NCCLS criteria, was determined by the agar dilution test with a Steers' replicator device to dispense a final inoculum of $10^{7} \mathrm{cfu} / \mathrm{L}$, according to NCCLS recommendations. ${ }^{15}$ Organisms with an MIC of amikacin > $16 \mathrm{mg} / \mathrm{L}$ were considered to be resistant. Aminoglycoside resistance profiles (AGRP) were determined by analysing susceptibility to tobramycin, dibekacin, amikacin, 5'-episisomicin, netilmicin, 2'-N-ethylnetilmicin, sisomicin, kanamycin, neomycin, paromomycin, ribostomycin, butirosin, gentamicin and isepamicin, as described previously. ${ }^{16}$

\section{Plasmids}

The plasmids utilised in this study are listed in table I. ${ }^{8,10,17,18}$ Plasmid pUC18 was obtained from a commercial source (Bethesda Research Laboratories, Gaithersburg, MD, USA).

\section{Conjugation and transformation}

Transfer of $\mathrm{R}$ plasmids from isolates of $S$. marcescens, $E$. coli, S. typhimurium, $C$. freundii, $K$. pneumoniae, K. oxytoca, Ent. cloacae, Proteus spp. and Acinetobacter spp. to E. coli $\mathrm{C} 2110$ was performed in L-broth at $37^{\circ} \mathrm{C}$. Transconjugants were selected on L-agar (Sigma) containing the following antibiotics at the indicated concentrations: nalidixic acid $25 \mathrm{mg} / \mathrm{L}$, and amikacin $20 \mathrm{mg} / \mathrm{L}$ or ampicillin $50 \mathrm{mg} / \mathrm{L}$. Transformation of $E$. coli HB101 with plasmid DNA was performed by the method of Hanahan. ${ }^{19}$ All transformants were assayed for susceptibility to amikacin, tobramycin, streptomycin, gentamicin, netilmicin, ampicillin, chloramphenicol, cefotaxime and cefoxitin by the disk-diffusion method, as described above.

\section{Isolation of plasmid DNA and restriction endonuclease analysis}

Plasmid DNA was prepared by the method of Birnboim and Doly. ${ }^{20}$ Restriction endonuclease cleavage of plasmid DNA was performed as recommended by the supplier (BRL). HindIII-digested $\lambda$-phage DNA and HaeIII-digested phage $\phi \times 174$ DNA (Pharmacia, Uppsala, Sweden) were included as molecular mass standards. Electrophoresis of DNA fragments was performed in horizontal agarose $0.8 \% \mathrm{w} / \mathrm{v}$ gels. ${ }^{21}$ Gels were stained with ethidium bromide $0.5 \mathrm{mg} / \mathrm{L}$ and photographs were obtained with Polaroid type 667 film under UV exposure. Cloning was performed according to a standard procedure described elsewhere. ${ }^{21}$ 
Southern blot hybridisation and labelling of plasmid DNA

Restriction fragments were transferred to nylon membranes by the Southern blot method..$^{22}$ Intragenic probes of $a a c\left(6^{\prime}\right)-I a, a a c\left(6^{\prime}\right)-I b, a a c\left(6^{\prime}\right)-I c$ and $a p h\left(3^{\prime}\right)$ VIa were prepared as described elsewhere. ${ }^{8,10,17,18}$ The intragenic probe of the $\operatorname{Tn} 1331$ transposase was a 2616-bp EcoRV DNA fragment obtained from pJHCMW1. ${ }^{10}$ A second probe specific for Tn 1331 comprised a $3 \cdot 0-\mathrm{kb}$ BamHI DNA fragment obtained from pJHCMW $1 .^{10}$ All fragments were isolated by electro-elution from agarose gels. Probes were labelled by the random-primer technique with ${ }^{32} \mathrm{P}$ dCTP ${ }^{21}$ All hybridisation experiments were performed under maximum stringent conditions as described previously. ${ }^{21}$ Dot-blot hybridisation experiments were performed by a standard procedure, as described elsewhere. ${ }^{21}$

\section{Results}

\section{Incidence of amikacin resistance}

Amikacin resistance increased steadily in several species throughout the study. From 1982 to the present time, amikacin has been used as the aminoglycoside of second choice, except in 1985 when it was selected as the aminoglycoside of first choice while gentamicin became the second choice. Resistance to gentamicin was a clinical problem during the study (1984-1991). The frequency of gentamicin-resistant isolates in different species was $60-70 \%$ in Klebsiella spp., $55-65 \%$ in Ent. cloacae, $90 \%$ in S. marcescens, $65 \%$ in C. freundii and $75-85 \%$ in Acinetobacter spp. These frequencies remained high throughout the study.

Table II summarises data on the incidence of amikacin resistance in Enterobacteriaceae and Acinetobacter spp. There was a 2-4-fold increase in the prevalence of amikacin resistance in isolates of Ent. cloacae, Klebsiella spp. and Acinetobacter spp., between 1984 and 1991 with a baseline of $\geqslant 10 \%$ in 1984. Among E. coli, Proteus spp. and C. freundii isolates, the average percentages of amikacin resis- tance were 2, 6 and $12 \%$, respectively, and remained relatively constant throughout the study (8 years). Resistance to amikacin in $S$. typhimurium appeared in a few isolates $(<1 \%)$ in 1990 . Rates of amikacin resistance in E. coli, Proteus spp., C. freundii and $S$. typhimurium did not differ significantly from those described in other hospitals from this country (table II). Rates of amikacin resistance in $S$. marcescens were the highest when compared with those from other species in $1984(42 \%)$ and reached $70 \%$ in 1986 . It should be noted that the incidence of resistance to amikacin in Klebsiella spp. and Acinetobacter spp. increased steadily throughout the study, and was higher overall than in $S$. marcescens.

\section{Genes involved in amikacin resistance}

A total of 127 clinical isolates from patients with nosocomial infection was selected in this period for further investigation. These isolates were resistant to five or more common antibiotics, including amikacin. Although it was not considered a selection criterion, $90 \%$ of the isolates were also resistant to gentamicin. The genes encoding amikacin resistance found in this study are summarised in table III. The presence of enzymes belonging to the $\mathrm{AAC}\left(6^{\prime}\right)$-I class is characterised by resistance to tobramycin, dibekacin, amikacin, 5'-episisomicin, netilmicin, 2'-ethylnetilmicin and sisomicin. At least six genes encoding this AGRP have been identified. ${ }^{6} \mathrm{We}$ analysed the bacterial population with probes currently available for the $a a c\left(6^{\prime}\right)-I a$, $a a c\left(6^{\prime}\right)-I b$ and $a a c\left(6^{\prime}\right)-I c$ genes. The frequency of these genes varied among the different species investigated and the $a a c\left(6^{\prime}\right)-I a$ gene was never found in 10 Acinetobacter isolates, $17 \mathrm{~K}$. pneumoniae, two E. coli and $10 S$. marcescens isolates. The aac ( $\left.6^{\prime}\right)$ $I c$ gene was detected by dot-blot hybridisation in every $S$. marcescens isolate and was the only amikacin resistance marker in $72 \%$ of these isolates. The aac $\left(6^{\prime}\right)$ $I b$ gene was found in five $S$. marcescens, one $E$. coli, one Ent. cloacae, $13 \mathrm{~K}$. pneumoniae, one K. oxytoca, two $C$. freundii, two Proteus spp. and two $S$. typhimurium isolates. Excluding Serratia and Acineto-

Table II. Percentages of amikacin-resistant isolates of Enterobacteriaceae and Acinetobacter spp. at the J. A. Fernández Hospital, and others, according to a local survey*

\begin{tabular}{|c|c|c|c|c|c|c|c|c|}
\hline \multirow{2}{*}{ Species } & \multicolumn{8}{|c|}{ Percentage of isolates that were AR in } \\
\hline & 1984 & 1985 & 1986 & 1987 & 1988 & 1989 & 1990 & 1991 \\
\hline E. coli & $0(3)$ & $0(2)$ & $1(1)$ & $1(2)$ & $1(1)$ & $2(1)$ & $1(1)$ & $1(6)$ \\
\hline Klebsiella spp. & $19(9)$ & $15(9)$ & $28(11)$ & $33(6)$ & $40(25)$ & $45(25)$ & $50(24)$ & $62(12)$ \\
\hline Proteus spp. & $5(6)$ & $4(3)$ & $6(2)$ & $8(4)$ & $5(2)$ & $6(13)$ & $7(5)$ & $7(3)$ \\
\hline Ent. cloacae & $10(9)$ & $15(22)$ & $17(5)$ & $18(21)$ & $21(20)$ & $23(11)$ & $20(24)$ & 21 (NA) \\
\hline C. freundii & $10(8)$ & $12(6)$ & $10(14)$ & $10(10)$ & $10(14)$ & $12(0)$ & $13(21)$ & 12 (NA) \\
\hline Salmonella spp. & $0(2)$ & $0(6)$ & $0(0)$ & $0(0)$ & $0(1)$ & $0(0)$ & $1(15)$ & 1 (NA) \\
\hline Serratia spp. & $42(17)$ & $31(17)$ & $70(12)$ & $41(36)$ & $28(33)$ & $0(22)$ & $40(23)$ & 0 (NA) \\
\hline Acinetobacter spp. & 19 (NA) & 22 (NA) & 25 (NA) & 38 (NA) & $49(55)$ & $56(20)$ & $63(51)$ & 75 (NA) \\
\hline
\end{tabular}

NA, not available.

*Numbers in parentheses represent data available from a local survey performed by the Comisión de Antibióticos, Asociación Argentina de Microbiología. The survey only included specimens retrieved from nosocomial infections. ${ }^{33}$ 
Table III. Amikacin resistance genes found in 127 isolates

\begin{tabular}{|c|c|c|c|c|c|}
\hline \multirow{2}{*}{ Species } & \multirow{2}{*}{$\begin{array}{l}\text { Number of } \\
\text { isolates }\end{array}$} & \multicolumn{4}{|c|}{ Frequency of appearance of each cloned gene } \\
\hline & & $a a c\left(6^{\prime}\right)-I b$ & $a a c\left(6^{\prime}\right)-I c$ & $\operatorname{aac}\left(6^{\prime}\right)-I^{*}$ & $a p h\left(3^{\prime}\right)-V I a$ \\
\hline E. coli & 2 & 1 & 0 & 0 & 1 \\
\hline$K$. pneumoniae & 17 & 13 & 0 & 0 & 4 \\
\hline K. oxytoca & 1 & 1 & 0 & 0 & 0 \\
\hline Proteus spp. & 2 & 2 & 0 & 0 & 0 \\
\hline Ent. cloacae & 2 & 1 & 0 & 0 & 1 \\
\hline C. freundii & 2 & 2 & 0 & 0 & 0 \\
\hline S. typhimurium & 2 & 2 & 0 & 0 & 0 \\
\hline S. marcescens & 49 & 5 & 49 & 0 & 9 \\
\hline Acinetobacter spp. & 50 & 0 & 0 & 10 & 40 \\
\hline
\end{tabular}

*This report.

bacter spp., the AAC $\left(6^{\prime}\right)$-I AGRP was found in combination with AGRPs associated with the AAC(3)-V enzymes in $40 \%$ of the isolates, with ANT( $\left.2^{\prime \prime}\right)$ in $20 \%$, and with both AAC(3)-V and ANT $\left(2^{\prime \prime}\right)$ in $40 \%$. Most Serratia isolates $(75 \%)$ had the triple combination of $\mathrm{AAC}(3)-\mathrm{V}+\mathrm{AAC}\left(6^{\prime}\right)$ I+APH $\left(3^{\prime}\right)-I$ AGRPs. The combination of these AGRPs causes the phenotype of resistance to gentamicin, tobramycin, netilmicin and amikacin, which were all aminoglycosides marketed in Argentina at the time of the study.

Ten Acinetobacter isolates expressing the AAC(6')-I AGRP failed to hybridise with any of the three probes described above (table III). Therefore, a 2700-bp $H$ indIII DNA fragment was cloned in pUC18 from a $15 \cdot 5-\mathrm{kb}$ acinetobacter plasmid. This fragment was able to encode the AAC $\left(6^{\prime}\right)-\mathrm{I}$ activity in $E$. coli $\mathrm{HB} 101$. Dot-blot hybridisation with this fragment as probe against 71 Enterobacteriaceae and 10 Acinetobacter isolates expressing the AAC $\left(6^{\prime}\right)-\mathrm{I}$ AGRP showed that only the Acinetobacter isolates hybridised with the probe. The fact that 71 Enterobacteriaceae, plus 20 other Acinetobacter isolates not expressing the AAC $\left(6^{\prime}\right)$-I activity, did not hybridise with the 2700-bp fragment demonstrated that the newly developed probe was specific enough for the purposes of this study. In Acinetobacter spp. the AAC(6')-I pattern occurred in combination with the AAC(3)-I AGRP.

The APH( $\left.3^{\prime}\right)-V I$ AGRP is associated with resistance to kanamycin, neomycin, paromomycin, ribostamycin, butirosin, gentamicin B, amikacin and isepamicin. It is known that there are at least two genes that encode this AGRP. ${ }^{6}$ The aph(3')-VIa gene was described by Lambert et al. ${ }^{23}$ in Acinetobacter spp. and, in this study, a probe developed by others from pSCH2010 was used. ${ }^{6}$ This probe hybridised with 40 Acinetobacter spp. $(80 \%$ of the Acinetobacter isolates), one $E$. coli, one Ent. cloacae, four $K$. pneumoniae and nine $S$. marcescens isolates $(20 \%$ of Enterobacteriaceae isolates). These percentages are considerably higher than those described by other authors, who have reported that the APH(3')-VI AGRP was present in $35.5 \%$ of Acinetobacter spp., $0.2 \%$ of Serratia spp. and $0.8 \%$ of gram-negative bacteria excluding Serratia spp., Acinetobacter spp. and Pseudomonas spp. ${ }^{6,18}$ One $K$. pneumoniae isolate had both the $a a c\left(6^{\prime}\right)-I b$ and the $a p h\left(3^{\prime}\right)-V I a$ genes encoding resistance to amikacin. The APH(3')-VI AGRP appeared in combination with AAC(3)-I (20\% of the isolates), AAC(3)-V (40\%) or ANT( 2 ") $(15 \%)$ AGRPs and determined the gentamicin-tobramycinnetilmicin-amikacin-isepamicin phenotype. No isolates with an AGRP consistent with the ANT(4')-I or the ANT(4")-I resistance mechanisms ${ }^{18}$ were found in the bacterial population investigated.

\section{Characterisation of amikacin resistance plasmids}

The occurrence of plasmids conferring resistance to amikacin in $42 \mathrm{AR}$ isolates was investigated by conjugation with $E$. coli $\mathrm{C} 2110$ or transformation of $E$. coli HB101, or both. These isolates included all Enterobacteriaceae that had hybridised with the $a a c\left(6^{\prime}\right)-I b$, or aph(3')-VIa genes. Ten Acinetobacter isolates were also tested but did not transfer any plasmid to $E$. coli $\mathrm{C} 2110$; transformation of $E$. coli with acinetobacter plasmids is, however, a rare event. $^{23,24}$ The $a a c\left(6^{\prime}\right)-I b$ gene was transferred, by transformation, from one $E$. coli, two Proteus spp., two $C$. freundii, one Ent. cloacae, five $S$. marcescens, 13 $K$. pneumoniae, one $K$. oxytoca and two $S$. typhimurium isolates to $E$. coli $\mathrm{HB} 101$. Amikacin resistance was associated with the presence of plasmid DNA between 10 and $20 \mathrm{~kb}$ in size. Five of these plasmids were mobilised in conjugation experiments with $E$. coli C2110. The plasmids recovered from transconjugants or transformants conferred resistance not only to amikacin, but also to tobramycin, streptomycin and ampicillin, and yielded 27 different restriction endonuclease fragment patterns after BamHI digestion. Digestion of all 27 plasmids with BamHI generated a 3000 -bp fragment that hybridised with the $a a c\left(6^{\prime}\right)-I b$ gene probe.

Plasmid DNA samples from one $E$. coli, four $K$. pneumoniae, one Ent. cloacae and nine $S$. marcescens isolates that carried the $a p h\left(3^{\prime}\right)-V I a$ gene were all conjugative and all transferred resistance to amikacin and ampicillin. Twelve different plasmids, with sizes from 20 to $60 \mathrm{~kb}$, were found in these 15 strains. One of these plasmids $(35 \mathrm{~kb}$ ) was found in four different 
a

$\mathrm{kb}$

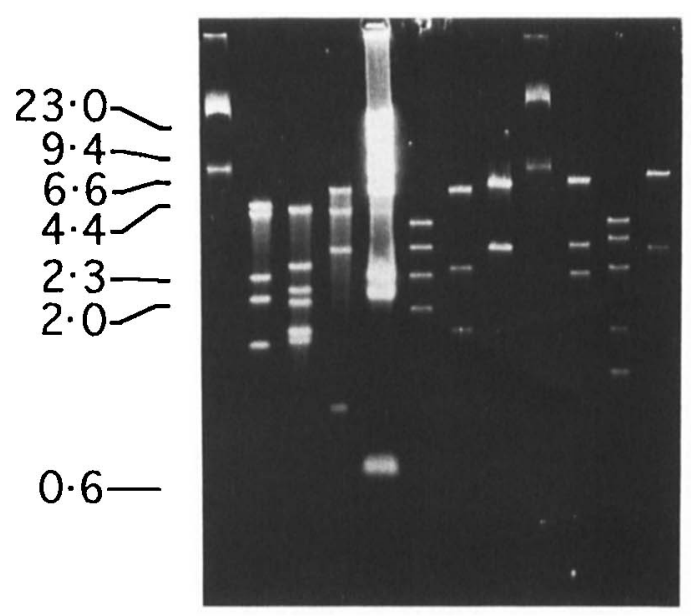

C

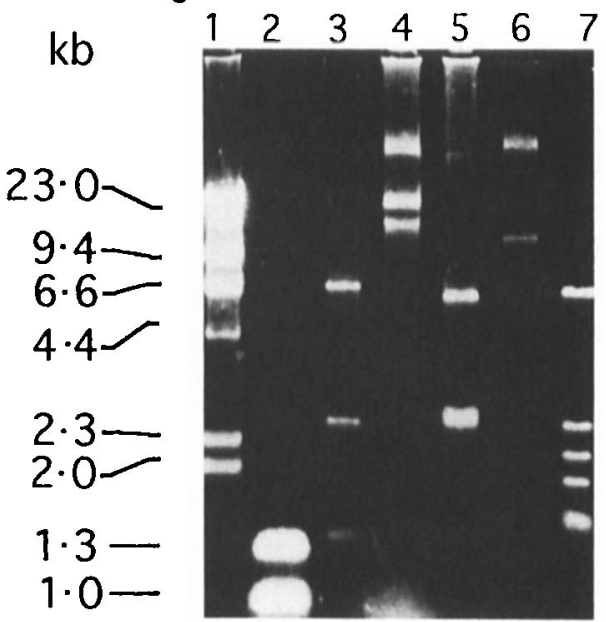

b

123456789101112

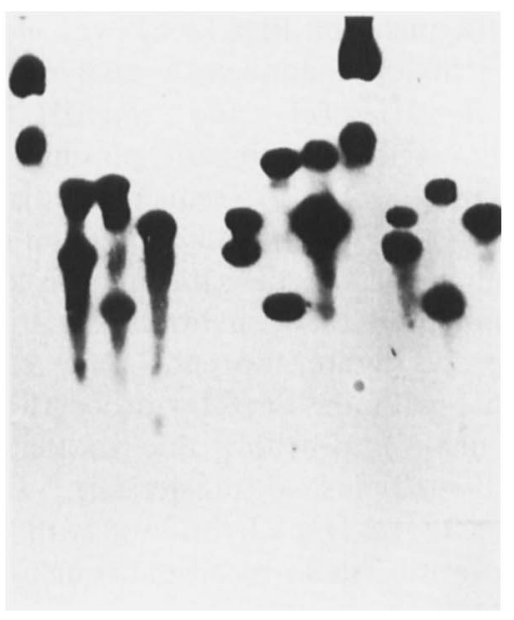

d

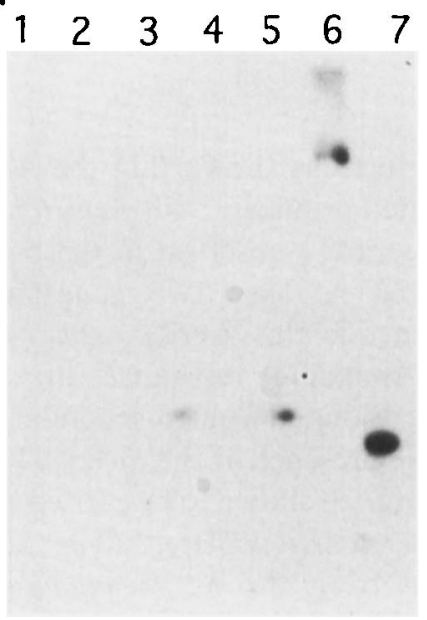

Figure. Analysis of Tn 1331 homology with pDCEC67 and pDCECL2; $\mathbf{a}$ and b, BamHI, EcoRV/SstI and BglI digestion and hybridisation of plasmid DNA. (a) Lane 1, pDCEC67 unrestricted; 2, pDCEC67 digested with $B g I ; 3$, pDCEC67 digested with EcoRV and $S s t I ; 4$, pDCEC67 digested with BamHI; 5, molecular mass marker ( $\lambda$-phage digested with HindIII); 6, pDCSP1 digested with BgII; 7, pDCSP1 digested with $E c o$ RV and $S s t \mathrm{I} ; 8, \mathrm{pDCSP} 1$ digested with BamHI; 9, pDCECL2 unrestricted; 10, pDCECL2 digested with BgII; 11, pDCECL2 digested with EcoRV and SstI; 12, pDCECL2 digested with BamHI. (b) Radio-autograph of Southern blot hybridisation of the gel in a with the 3-kb BamHI pJHCMWl fragment as probe. c and d, $E c o$ RV digestion and hybridisation of plasmid DNA. (c) lane 1, molecular mass marker ( $\lambda$-phage digested with HindIII); 2, molecular mass marker (phage $\phi \times 174$ digested with HaeIII);3, pJHCMW1 digested with EcoRV; 4, pDCECL2 unrestricted; 5, pDCECL2 digested with EcoRV; 6, pDCEC67 unrestricted; 7, pDCEC67 digested with EcoRV. (d) Radioautograph of Southern blot hybridisation of gel $\mathbf{c}$ with the 2.616-kb EcoRV pJHCMW1 fragment as probe for the Tn 1331 transposase.

isolates. These four plasmids carried the $a p h\left(3^{\prime}\right)-V I a$ gene in a $4 \cdot 7-\mathrm{kb}$ BamHI DNA fragment. One plasmid, from an $E$. coli isolate, also encoded resistance to cefotaxime and cefoxitin. The $a a c\left(6^{\prime}\right)-I b$ and $a p h\left(3^{\prime}\right)$ $V I a$ genes, present in a single strain of $K$. pneumoniae, were located to two different plasmids.

\section{Presence of DNA sequences related to Tn1331}

Dot-blot analysis of the 127 amikacin-resistant isolates with an intragenic probe of the $\operatorname{Tn} 1331$ transposase revealed that only those bearing the $a a c\left(6^{\prime}\right)-I b$ gene hybridised with the probe. Plasmid DNA from the 27 transformants carrying the $a a c\left(6^{\prime}\right)$ $I b$ gene was digested with $B a m \mathrm{HI}, B g I \mathrm{I}$ and $E c o \mathrm{RV} /$
Sst I and hybridised with a 3-kb BamHI DNA fragment specific for $\operatorname{Tn} 1331$. The results revealed that 26 of the plasmids exhibited a hybridisation pattern indicative of transposon Tn1331 (figure). Plasmid pDCECL2 from one Ent. cloacae isolate, for example, exhibited a hybridisation pattern similar to that of $\mathrm{pDCSP} 1^{25}$ carrying Tn 1331 (figure). Plasmid DNA from all 27 isolates digested with $E c o \mathrm{RV}$ and hybridised against the intragenic probe of the $\operatorname{Tn} 1331$ transposase revealed that 26 plasmids hybridised in the $2 \cdot 6-\mathrm{kb}$ $E c o$ RV DNA fragment. Plasmid DNA from E. coli isolate 67 (EC67) hybridised in a $2 \cdot 0-\mathrm{kb}$ EcoRV DNA fragment. Plasmid DNA from EC67 (pDCEC67) exhibited a different Tn1331 hybridisation pattern, although the plasmid shared certain homology in 
different fragments (figure). In spite of these differences, pDCEC67 had a 3.0-kb BamHI DNA fragment similar to that exhibited by $\operatorname{Tn} 1331$. To analyse sequences adjacent to the $a a c\left(6^{\prime}\right)-I b$ gene, the $3 \cdot 0-\mathrm{kb}$ BamHI fragment of PDCEC67 was cloned into pUC18. Restriction endonuclease analysis with $B a m \mathrm{HI} / A v a \mathrm{I}, \quad B a m \mathrm{HI} / X h o \mathrm{I}$ and BamHI/KpnI demonstrated that this recombinant plasmid had similar, if not identical, $a a c\left(6^{\prime}\right)-I b$ sequences adjacent to Tn1331 (data not shown). Finally, although conditions for hybridisation were the same in both cases, undigested plasmid pDCECL2 hybridised with the $3 \cdot 0-\mathrm{kb}$ Tn 1331 probe (figure, top panel, lane 9) but failed to hybridise with the 2616-bp probe (figure, bottom panel, lane 4), probably due to the low efficiency of undigested plasmid transference. ${ }^{21}$ However, digested pDCECL2 DNA hybridised with both probes, which permitted us to reach the conclusions presented here.

\section{Discussion}

A previous report has shown that the APH(3')-VI AGRP is associated primarily with Acinetobacter spp. $(35.4 \%)$ and was rarely observed in the other gramnegative bacteria. ${ }^{6}$ At least two genes have been identified that encode this AGRP, aph(3')-VIa and $a p h\left(3^{\prime}\right)-V I b .^{6,9}$ Amikacin resistance in strains of Acinetobacter spp. isolated from nosocomial infections was related to the presence of the $\operatorname{aph}\left(3^{\prime}\right)-V I a$ gene. ${ }^{24}$ This gene has also been shown to be carried by $\operatorname{Tn} 1528$ in a Providencia stuartii isolate. ${ }^{26}$ The aph $\left(3^{\prime}\right)-V I b$ gene was cloned from the $K$. pneumoniae plasmid pRPG $101^{27}$ but DNA hybridisation studies were not performed to show the relationship between this gene and the aph(3')-VIa from Acinetobacter spp. ${ }^{6}$ Surprisingly, in this study with Enterobacteriaceae, aph $\left(3^{\prime}\right)-V I a$, a gene confined so far to Acinetobacter spp., was also found in plasmids of $S$. marcescens, $K$. pneumoniae, Ent. cloacae and E. coli $(20 \%)$. In the remaining $80 \%$, as expected, the AAC(6 $\left.6^{\prime}\right)$-I AGRP was responsible for resistance to amikacin. Two genes were found in the Enterobacteriaceae population encoding this AGRP. These were the $a a c\left(\sigma^{\prime}\right)-I b$ and the aac $\left(6^{\prime}\right)-I c$ genes. $^{8,28}$ The former was described previously in plasmid DNA from $K$. pneumoniae, $E$. coli and $S$. marcescens. ${ }^{5,28-30}$ This gene was also found in plasmid DNA from Proteus spp., S. typhimurium, Ent. cloacae, $K$. oxytoca and $C$. freundii. The latter gene was found in $72 \%$ of $S$. marcescens isolates as the sole mechanism of resistance to amikacin. The only gene consistently found in both Acinetobacter spp. and Enterobacteriaceae was aph(3')-VIa. Furthermore, one $K$. pneumoniae isolate harboured two R-plasmids, one carrying the $a p h\left(3^{\prime}\right)-V I a$ and the other the $a a c\left(6^{\prime}\right)$ $I b$ gene. The species that harboured the highest number of gene types conferring amikacin resistance was $S$. marcescens, which carried aac( $\left.6^{\prime}\right)-I b$, aac( $\left.6^{\prime}\right)-I c$ and $\operatorname{aph}\left(3^{\prime}\right)$-VIa genes.
DNA from $20 \%$ of those Acinetobacter isolates expressing the AAC(6')-I AGRP did not hybridise with $a a c\left(6^{\prime}\right)-I a$, $a a c\left(6^{\prime}\right)-I b$ or $a a c\left(6^{\prime}\right)-I c$ probes. Preliminary cloning studies from this laboratory revealed that this activity was located in a $15 \cdot 5-\mathrm{kb}$ plasmid from an Acinetobacter sp. A probe developed from this plasmid hybridised with those Acinetobacter isolates, whereas none of the Enterobacteriaceae isolates hybridised with this probe. This may represent the finding of a new gene, or another amongst other genes that have been reported recently, after this study was completed. ${ }^{6,31,32}$ Further studies are required to identify and characterise this gene. Although resistance to gentamicin was not used as a criterion for selecting AR strains, AAC(3)-V, ANT(2")-I and AAC(3)-I AGRPs were found in $90 \%$ of the isolates, in combination with other mechanisms. The gentamicin-tobramycin-netilmicin-amikacin (the sole aminoglycosides marketed in Argentina during the study) phenotype was common in this survey because of the high incidence $(55 \%)$ of isolates with the combination of $\mathrm{AAC}(3)-\mathrm{V}$ with $\mathrm{APH}\left(3^{\prime}\right)-\mathrm{VI}$ or AAC $\left(6^{\prime}\right)-I$ AGRPs, or both. These combinations were found more frequently in our survey than in a survey reported by others. ${ }^{6}$ It should be noted that in our bacterial population the combination of $\mathrm{AAC}(3)-\mathrm{V}$ with APH(3')-VI or AAC (6')-I AGRPs, or both, was not located on broad host range plasmids because the $a a c\left(6^{\prime}\right)-I b$ and the $a p h\left(3^{\prime}\right)-V I a$ genes were always found in plasmids that did not transfer the gentamicin resistance.

The frequency of nosocomial infections due to AR gram-negative bacilli was documented in the USA in 1985 and the rates ranged from 0.8 to $3.5 \%{ }^{2-4}$ The rates found in Argentina ${ }^{33}$ are remarkably higher than those found in the USA and Europe. ${ }^{2,6,24,34}$ Because, surprisingly, high rates of aminoglycoside resistance are found in isolates from most hospitals in Argentina, extreme care is routinely taken when assessing antimicrobial susceptibility. All isolates in this study were investigated by both disk diffusion and agar dilution tests and quality control was performed as recommended by NCCLS. ${ }^{15}$ The fact that not only in our hospital, but also in other hospitals in Argentina, ${ }^{33}$ similar high rates of AR gram-negative bacilli have been found, lends credibility to our unusual findings and led us to design the present study. Thirty-one percent of all $S$. marcescens and $15 \%$ of all Acinetobacter and Klebsiella isolates from patients suffering from nosocomial infections in our hospital were resistant to amikacin in 1985. These resistance rates were not uniform and a steady increase in amikacin resistance was observed following modifications in aminoglycoside usage, although there is no proof that a cause-effect phenomenon has taken place. When aminoglycoside resistance mechanisms were investigated, it was seen that an unusually high number of isolates carried the combination of $\mathrm{AAC}(3)-\mathrm{V}$ or AAC(3)-I with AAC(6')-I or APH(3')-VI AGRPs, which conferred resistance to both amikacin and gen- 
tamicin. The species that carried the aph(3')-VIa gene with a frequency higher than that reported previously by others, ${ }^{6}$ were the ones usually involved in nosocomial infections and exhibited high rates of amikacin resistance. Ecological factors such as poor environmental control, which favour spreading of R-plasmids, may have also contributed to the maintenance of amikacin resistance. It is interesting to note that AAC $\left(6^{\prime}\right)$-I group enzymes are capable of inactivating amikacin but only cause resistance, according to the standards set by NCCLS, when the enzymic activity is expressed at high levels. Therefore, it is important to decide, according to the design of the study, the precise cut-off to determine which specimens would be considered. Because only isolates with an MIC $>16 \mathrm{mg} / \mathrm{L}$ were included in this study, the high percentage of those expressing the APH(3')-VI AGRP is not an artifact, due to missing specimens bearing AAC (6 $\left.6^{\prime}\right)-\mathrm{I}$, but a true estimate of the incidence of $\mathrm{APH}\left(3^{\prime}\right)-\mathrm{VI}$ AGRP.

Previous reports have shown that outbreaks due to amikacin-resistant Enterobacteriaceae usually involve single plasmid species carrying the $a a c\left(6^{\prime}\right)-I$ genes. ${ }^{5,29}$ Hopkins et al. described four plasmids from 21 Enterobacteriaceae isolates. ${ }^{5}$ For another aminoglycoside gene, the same epidemic plasmid was found worldwide.$^{35}$ Enterobacteriaceae described in this report harboured at least 42 plasmid species mediating the $a a c\left(6^{\prime}\right)-I b$ or the $a p h\left(3^{\prime}\right)-V I a$ genes; $48 \%$ of these plasmids were conjugative, which indicates conjugation as a likely mechanism mediating the spread of amikacin resistance.

Different aac (6 $\left.6^{\prime}\right)-I$ genes may be found in transposons of the Tn 3 family. ${ }^{5,9,10}$ More recent data have suggested that $\operatorname{Tn} 21$ contains a specific region, the integron, into which many different resistance genes may be inserted. ${ }^{6,36}$ In the light of this information, dissemination of these transposons was investigated in

\section{References}

1. Garcia DC, Trevisán AR, Botto L, Cervetto M, Sarubbi MA, Zorzopulos J. An outbreak of multiply resistant Pseudomonas aeruginosa in a neonatal unit: plasmid pattern analysis. J Hosp Infect 1989; 14: 99-105.

2. Larson TA, Garrett CR, Gerding DN. Frequency of aminoglycoside 6 -N-acetyltransferase among Serratia species during increased use of amikacin in the hospital. Antimicrob Agents Chemother 1986; 30: 176-178.

3. Gerding DN, Larson TA, Hughes RA, Weiler M, Shanholtzer $C$, Peterson LR. Aminoglycoside resistance and aminoglycoside usage: ten years of experience in one hospital. Antimicrob Agents Chemother 1990; 35: 1284-1290.

4. Levine JF, Maslow MJ, Leibowitz RE et al. Amikacin-resistant Gram-negative bacilli: correlation of occurrence with amikacin use. J Infect Dis 1985; 151: 295-300.

5. Hopkins JD, Flores A, Pilar-Pla M, Lester S, O'Brien TF. Nosocomial spread of an amikacin resistance gene on both a mobilized, nonconjugative plasmid and a conjugative plasmid. Antimicrob Agents Chemother 1991; 35: 1605-1611.

6. Shaw KJ, Rather PN, Hare RS, Miller GH. Molecular genetics of aminoglycoside resistance genes and familial relationships of the aminoglycoside-modifying enzymes. Microbiol Rev 1993 ; 57: 138-163. all AR isolates. Hybridisation strategies were used for this purpose, including an intragenic probe of the Tn1331 transposase that has a nucleotide sequence identical to that of $\operatorname{Tn} 3$ and $\operatorname{Tn} 21 .{ }^{10}$ In this study we identified $\mathrm{Tn} 1331$-related sequences solely in plasmids harbouring the $a a c\left(6^{\prime}\right)-I b$ gene. This gene was found in all 27 plasmids in a 3.0-kb BamHI fragment. Cloning and restriction analysis of this BamHI fragment with four endonucleases revealed that sequences adjacent to the $a a c\left(6^{\prime}\right)-I b$ gene were identical in pDCEC67, a plasmid that displayed other genetic dissimilarities at the level of the Tn1331 transposase gene. Conversely, in a study that described four plasmids carrying Tn3related transposons from 21 nosocomial outbreak isolates, Hopkins et al. showed that sequences adjacent to $a a c\left(6^{\prime}\right)-I$ alleles were different. ${ }^{5}$ Because all plasmids were different by restriction endonuclease analysis, several possible sources for $\operatorname{Tn} 1331$ are suggested: (i) the dissemination of $\operatorname{Tn} 1331$ may have been due to transposition mechanisms which occurred after intraor inter-species transference; (ii) after transfer of a plasmid carrying $\operatorname{Tn} 1331$, a process of plasmid recombination may have been responsible for the appearance of $\mathrm{Tn} 1331$ in different plasmids; (iii) although unlikely, all isolates carrying different plasmids may have originated from different infection sources; or (iv) a combination of these mechanisms. Because the rate of AR isolates varied within each species in spite of the presence of $\operatorname{Tn} 1331$, it is concluded that this transposon may not be the sole factor responsible for the observed variation.

We thank Drs G. H. Miller and K. J. Shaw (Schering Corp., Kenilworth, NJ, USA) for providing plasmids pFCT1165, pSCH2010 and pSCH2014, and Dr M. E. Tolmasky for providing plasmid pJHCMW1. We also thank Dr Mariana Catalano for her critical review of the manuscript. This study was supported in part by BioSidus (Buenos Aires, Argentina). D.C.G. is the recipient of a research fellowship from the University of Buenos Aires, Argentina.

7. Shimizu K, Kumada T, Hsieh WC et al. Comparison of aminoglycoside resistance patterns in Japan, Formosa, and Korea, Chile, and the United States. Antimicrob Agents Chemother 1985; 28 : 282-288.

8. Shaw KJ, Rather PN, Sabatelli FJ et al. Characterization of the chromosomal aac $\left(6^{\prime}\right)-I c$ gene from Serratia marcescens. Antimicrob Agents Chemother 1992; 36: 1447-1455.

9. Meyer JF, Nies BA, Wiedemann B. Amikacin resistance mediated by multiresistance transposon $\operatorname{Tn} 2424$. J Bacteriol 1983; 155: 755-760.

10. Tolmasky ME, Crosa JH. Tn1331, a novel multiresistance transposon encoding resistance to amikacin and ampicillin in Klebsiella pneumoniae. Antimicrob Agents Chemother 1987; 31 : 1955-1960.

11. Boyer HW, Roulland-Dussoix D. A complementation analysis of the restriction and modification of DNA in Escherichia coli. J Mol Biol 1969; 41: 459-472.

12. Ditta G, Stanfield S, Corbin D, Helinski DR. Broad host range DNA cloning system for gram-negative bacteria: construction of a gene bank of Rhizobium meliloti. Proc Natl Acad Sci USA 1981; 77: 7347-7351.

13. Kelly MT, Brenner DJ, Farmer JJ. Enterobacteriaceae. In: Lennette EH (ed) Manual of clinical microbiology, 4th edn. Washington DC, American Society for Microbiology, 1985: 263-281.

14. Bauer A, Kirby W, Sherris J et al. Antibiotic susceptibility 
testing by a standardized single disk method. Am J Clin Pathol 1966; 45: 493-496.

15. National Committee for Clinical Laboratory Standards. Methods for dilution antimicrobial susceptibility tests for bacteria that grow aerobically. Approved standard M7A2. National Committee for Clinical Laboratory Standards, Vilanova, Pennsylvania.

16. Miller GH, Sabatelli FJ, Hare RS, Waitz JA. Survey of aminoglycoside resistance patterns. Dev Ind Microbiol 1980; $21: 91-104$.

17. Tenover FC, Filpula D, Phillips KL, Plorde JJ. Cloning and sequencing of a gene encoding an aminoglycoside $6^{\prime}-\mathrm{N}$ acetyltransferase from an $\mathrm{R}$ factor of Citrobacter diversus. $J$ Bacteriol 1988; 170: 471-473.

18. Shaw KJ, Hare RS, Sabatelli FJ et al. Correlation between aminoglycoside resistance profiles and DNA hybridization of clinical isolates. Antimicrob Agents Chemother 1991; 35 : 2253-2261

19. Hanahan D. Mechanisms of DNA transformation. In: Neidhardt FC (ed) Escherichia coli and Salmonella typhimurium: cellular and molecular biology, vol 2 . Washington DC, American Society for Microbiology. 1987: 1177-1183.

20. Birnboim HC, Doly J. A rapid alkaline extraction procedure for screening recombinant plasmid DNA. Nucleic Acids Res 1979; $7: 1513-1516$.

21. Sambrook J, Fritsch EF, Maniatis T. Molecular cloning: a laboratory manual, 2nd edn. Cold Spring Harbor, NY, Cold Spring Harbor Laboratory. 1989.

22. Southern EM. Detection of specific sequences among DNA fragments separated by gel electrophoresis. $J \mathrm{Mol}$ Biol 1975; 98 : 503-517.

23. Lambert T, Gerbaud G, Courvalin P. Transferable amikacin resistance in Acinetobacter spp. due to a new type of 3 'aminoglycoside phosphotransferase. Antimicrob Agents Chemother $1988 ; 32: 15-19$.

24. Lambert T, Gerbaud G, Bouvet P, Vieu JF, Courvalin P. Dissemination of amikacin resistance gene aphA6 in Acinetobacter spp. Antimicrob Agents Chemother 1990; 34: 1244-1248.

25. Centrón García D. Molecular basis of amikacin resistance in bacteria from the hospital environment ( $\mathrm{PhD}$ Thesis). Buenos Aires, Argentina: University of Buenos Aires 1994.

26. Lambert T, Gerbaud G, Courvalin P. Characterisation of transposon $\mathrm{Tn} 1528$ conferring amikacin resistance in Enterobacteriaceae by synthesis of a $3^{\prime}$-aminoglycoside phosphotransferase type VI. Abstracts of the 31st Interscience Conference on Antimicrobial Agents and Chemotherapy. Chicago, IL, American Society for Microbiology. 1991; Abstract no. 1360: 325.

27. Gaynes R, Groisman E, Nelson E, Casadaban M, Lerner SA. Isolation, characterization, and cloning of a plasmid-borne gene encoding a phosphotransferase that confers high-level of amikacin resistance in enteric bacilli. Antimicrob Agents Chemother 1988; 32: 1379-1384.

28. Tolmasky ME, Roberts M, Woloj M, Crosa JH. Molecular cloning of amikacin resistance determinants from a Klebsiella pneumoniae plasmid. Antimicrob Agents Chemother 1986; 30: 315-320.

29. Van Nhieu GT, Goldstein FW, Pinto ME, Acas JF, Collatz E. Transfer of amikacin resistance by closely related plasmids in members of the family Enterobacteriaceae isolated in Chile. Antimicrob Agents Chemother 1986; 29 : 833-837.

30. Tran Van Nhieu G, Collatz E. Primary structure of an aminoglycoside $6^{\prime}-\mathrm{N}$-acetyltransferase, AAC $\left(6^{\prime}\right)-4$, fused in vivo with the signal peptide of the Tn 3-encoded $\beta$ lactamase. J Bacteriol 1987; 169 : 5708-5714.

31. Lambert $T$, Gerbaud $G$, Galimand $M$, Courvalin $P$. Characterization of Acinetobacter haemolyticus aac $\left(6^{\prime}\right)-I g$ gene encoding an aminoglycoside $6^{\prime}$ - $\mathrm{N}$-acetyltransferase which modifies amikacin. Antimicrob Agents Chemother 1993; 37 : 2093-2100.

32. Vanhoof $\mathrm{R}$, Content J, Van Bossuyt $\mathrm{E}$ et al. Use of the polymerase chain reaction (PCR) for the detection of aac $A$ genes encoding aminoglycoside- $6^{\prime}-\mathrm{N}$-acetyltransferases in reference strains and gram-negative clinical isolates from two Belgium hospitals. J Antimicrob Chemother 1993; 32: 23-25.

33. Sociedad Argentina de Bacteriología Clínica. Annual Reports of the Subcomisión de Antimicrobianos. Asociación Argentina de Microbiología, Buenos Aires, 1984-1989.

34. Milosovic P, Macicková T, Kettner M, Kallová J. Development of amikacin resistance in bacterial isolates in Slovakia (1990-1992). Int J Antimicrob Agents 1994; 4: 69-71.

35. O’Brien TF, Plá M del P, Mayer KH et al. Intercontinental spread of a new antibiotic resistance gene on a epidemic plasmid. Science $1985 ; 230$ : 87-88.

36. Ouellette $\mathrm{M}$, Bissonnette L, Roy $\mathbf{P H}$. Precise insertion of antibiotic resistance determinants into Tn2I-like transposons: nucleotide sequence of the OXA-1 $\beta$-lactamase gene. Proc Natl Acad Sci USA 1987; 84: 7378-7382. 